\title{
Sex Differences in Regional Brain Glucose Metabolism Following Opioid Withdrawal and Replacement
}

\author{
Giovanni C Santoro',4, Joseph Carrion ',4, Krishna Patel', Crystal Vilchez', Jennifer Veith', Jonathan D Brodie ${ }^{2}$ \\ and Stephen L Dewey*,1,2,3 \\ 'Center for Neurosciences, Laboratory for Molecular and Behavioral Neuroimaging, Feinstein Institute for Medical Research, Manhasset, NY, USA; \\ ${ }^{2}$ Psychiatry Department, New York University School of Medicine, New York, NY, USA; ${ }^{3}$ Department of Molecular Medicine, Hofstra Northwell \\ School of Medicine, Hempstead, NY, USA
}

\begin{abstract}
Methadone and buprenorphine are currently the most common pharmacological treatments for opioid dependence. Interestingly, the clinical response to these drugs appears to be sex specific. That is, females exhibit superior therapeutic efficacy, defined as extended periods of abstinence and longer time to relapse, compared with males. However, the underlying metabolic effects of opioid withdrawal and replacement have not been examined. Therefore, using ${ }^{18} \mathrm{FDG}$ and microPET, we measured differences in regional brain glucose metabolism in males and females following morphine withdrawal and subsequent methadone or buprenorphine replacement. In both males and females, spontaneous opioid withdrawal altered glucose metabolism in regions associated with reward and drug dependence. Specifically, metabolic increases in the thalamus, as well as metabolic decreases in insular cortex and the periaqueductal gray, were noted. However, compared with males, females exhibited increased metabolism in the preoptic area, primary motor cortex, and the amygdala, and decreased metabolism in the caudate/putamen and medial geniculate nucleus. Methadone and buprenorphine initially abolished these changes uniformly, but subsequently produced their own regional metabolic alterations that varied by treatment and sex. Compared with sex-matched control animals undergoing spontaneous opioid withdrawal, male animals treated with methadone exhibited increased caudate/putamen metabolism, whereas buprenorphine produced increased ventral striatum and motor cortex metabolism in females, and increased ventral striatum and somatosensory cortex metabolism in males. Notably, when treatment effects were compared between sexes, methadone-treated females showed increased cingulate cortex metabolism, whereas buprenorphine-treated females showed decreased metabolism in cingulate cortex and increased metabolism in the globus pallidus. Perhaps the initial similarities in males and females underlie early therapeutic efficacy, whereas these posttreatment sex differences contribute to clinical treatment failure more commonly experienced by the former.

Neuropsychopharmacology (2017) 42, I84I-1849; doi:I0.1038/npp.2017.69; published online 3 May 2017
\end{abstract}

\section{INTRODUCTION}

Opioid abuse is an urgent public healthcare concern. The 2014 National Survey on Drug Use and Health estimated that 4.3 million Americans used prescription pain relievers nonmedically (Center for Behavioral Health Statistics and Quality, 2015). In addition, although they constitute only $5.6 \%$ of the world's populations, Americans consume $\sim 80 \%$ of the global opioid supply, $99 \%$ of the global hydrocodone supply, and two-thirds of the world's illegal drugs (Manchikanti et al, 2010; NIDA, 1991). The surge in opioid abuse has been attributed to factors including the social acceptance of medications, the aggressive culture of

\footnotetext{
*Correspondence: Dr SL Dewey, Director and Investigator, Laboratory for Molecular and Behavioral Neuroimaging, Center for Neurosciences, Feinstein Institute for Medical Research, Manhasset, NY I I030, USA, Tel: 5 I 6562 2357, E-mail: sdewey@northwell.edu

${ }^{4}$ These authors contributed equally to this work.

Received 8 November 2016; revised 30 March 2017; accepted 3 April 2017; accepted article preview online 10 April 2017
}

pharmaceutical advertising, and the increasing availability of prescription analgesics (Chang et al, 2014; Daubresse et al, 2013). Subsequently, concerns have been raised over drug prescribing patterns (Compton and Volkow, 2006), the social and economic costs of opioid addiction (Connock et al, 2007; McCarty et al, 2010; Polsky et al, 2010; Schackman et al, 2012), as well as the safety (Maremmani and Gerra, 2010), availability (Bonhomme et al, 2012; Nosyk et al, 2013; Novick et al, 2015) and expansion of current treatment options, mainly methadone (METH) and buprenorphine (BUP) replacement (Bonhomme et al, 2012; Kraus et al, 2011; Wesson and Smith, 2010).

METH is an agonist of $\mu$-opioid receptors. These G-proteincoupled receptors modulate dopamine, a catecholamine neurotransmitter that regulates reward-motivated behavior (Spanagel and Weiss, 1999). METH is a lipid-soluble compound, and although its analgesic duration of action is only 4 to $8 \mathrm{~h}$, it has a relatively long half-life of 8 to $59 \mathrm{~h}$ and a high oral bioavailability. This allows for continuous receptor occupation and effective opioid maintenance 
(Ball and Ross, 1991; Dole, 1989; Eap et al, 2002; Ward et al, 1999). However, METH has been used and sold by opioiddependent individuals seeking to subsidize the cost of illicit drug use (Davis and Johnson, 2008). Therefore, because of its potential for abuse, it must be administered in a supervised setting, thus creating logistic and compliance concerns (Haskew et al, 2008). In addition, METH detoxification can produce severe withdrawal lasting several days to weeks (Eap et al, 2002). In current clinical practice it is titrated to a therapeutic level that prevents withdrawal without requiring increased dosing. However, effective clinical dosing often varies substantially (Trafton et al, 2006). Emerging as an alternative to METH is Suboxone, which is BUP prepared with naloxone. This formulation enables its use as a prescription drug in primary care settings. When taken orally, its partial $\mu$-opioid agonist activity allows for successful opioid replacement and maintenance. However, if Suboxone tablets are crushed, dissolved, and injected or insufflated, the antagonistic effects of naloxone in the preparation causes immediate opioid withdrawal, thereby limiting recreational diversion. This formulation has gained popularity in clinical detoxification settings because of its less intense withdrawal severity (Ling et al, 1996), but although Suboxone is effective for treating moderate opioid dependence, high levels of dependence usually require METH (Johnson et al, 2000).

Although these pharmacotherapies represent first-line treatments for opioid withdrawal, their efficacies are variable (Johnson et al, 2000). This is thought to be due in part to personal motivation and treatment adherence. However, there is an understudied observation that sex significantly affects therapeutic response, which is often measured as time to relapse. A 25-year follow-up of heroin-dependent patients prescribed METH indicated that surviving women were significantly more likely than men to have stopped heroin use (Jimenez-Trevino et al, 2011). Similarly, a 7-year followup study of heroin-dependent patients treated with BUP showed that, again, women were significantly more likely than men to have stopped heroin use (Ohlin et al, 2015). Finally, Sheynin et al (2016) observed that only males receiving replacement therapy (METH or BUP) demonstrated abnormal avoidance behavior.

Differences in rates of substance abuse and dependence have long been reported. Specifically, women are generally considered more susceptible to drug cravings and relapse (Fox et al, 2014; Hitschfeld et al, 2015; Kennedy et al, 2013; Kippin et al, 2005; Robbins et al, 1999; Rubonis et al, 1994). Men are more likely to abuse illicit drugs, but women are just as likely to develop drug dependence (Anthony et al, 1994). Despite these findings, there continues to be a marked paucity of studies focused on the development of potential sex-directed pharmacological interventions.

In an effort to better understand these reported sex-specific differences in treatment efficacy, we imaged adolescent male and female animals using micro-positron emission tomography (microPET) in combination with ${ }^{18}$ F-fluorodeoxyglucose $\left({ }^{18} \mathrm{FDG}\right)$ following morphine

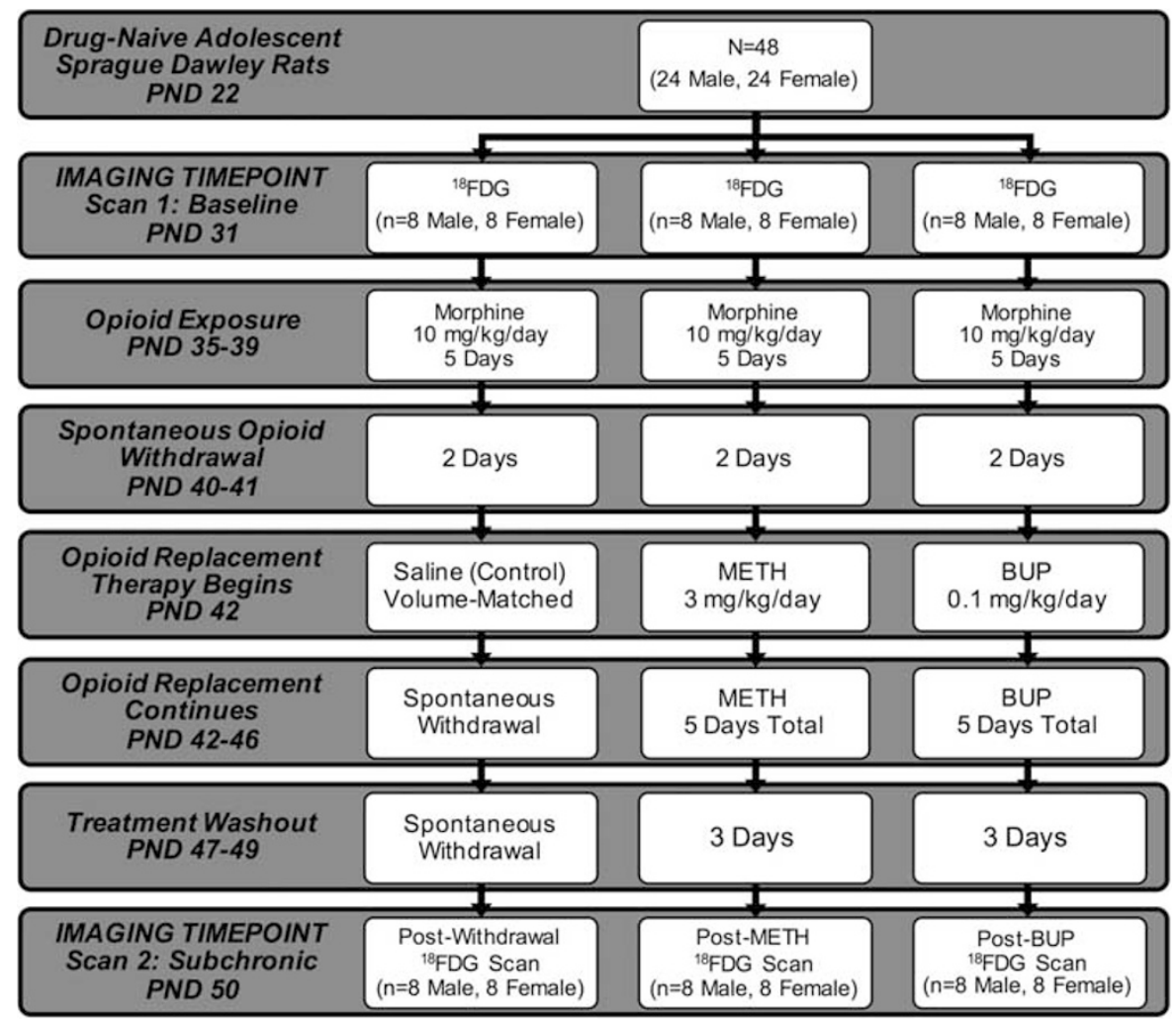

Figure I Experimental timeline. This flowchart provides a summary of the experimental timeline. From top to bottom, the progression of ${ }^{18} \mathrm{FDG}$ microPET scans and treatment with morphine, methadone (METH), and buprenorphine (BUP) is delineated by postnatal day (PND). Scan I refers to the baseline (pretreatment) imaging time point. Scan 2 refers to images obtained after spontaneous withdrawal (control), subchronic METH replacement, and subchronic BUP replacement. Study group drug dosing, treatment duration, and sample size are noted in the figure. 
cessation and subsequent METH or BUP replacement. For this study, BUP was chosen rather than Suboxone so as to not potentially confound the metabolic representation of the primary treatment modality. Adolescent animals were chosen as this age group is generally associated with incipient drug use, lifetime developmental consequences of drug exposure (Vassoler et al, 2014), as well as gestational complications following opioid abuse (Ross et al, 2015). Each of these factors may be due, at least in part, to neuronal pairing, incomplete maturation of frontal cortices, and elevated levels of brain glucose metabolism, all of which are hallmarks of the adolescent brain. We postulated that sex likely influences neural pathways associated with reward and addiction. Specifically, we hypothesized that male and female rats would respond uniquely to opioid withdrawal and replacement as represented by regional changes in brain glucose metabolism.

\section{MATERIALS AND METHODS}

Figure 1 provides a concise summary and timeline of the methods used in this study, as well as the number of animals per group. Drug-naive adolescent male and female SpragueDawley rats from Taconic Farms arrived on postnatal day (PND) 22. Animals were maintained on a $12 \mathrm{~h}$ light-dark cycle and received food and water ad libitum. Before each scan, animals were fasted for $12 \mathrm{~h}$ to ensure blood glucose stability (Fueger et al, 2006; Wong et al, 2011). Following an acclimation period (9 days), all animals received baseline ${ }^{18}$ FDG microPET scans on PND 31 (scan 1). On PND 35, animals commenced morphine treatment for 5 days at a dose of $10 \mathrm{mg} / \mathrm{kg} /$ day subcutaneously. This dose was selected based on data indicating that $10 \mathrm{mg} / \mathrm{kg}$ was adequate to achieve conditioned place preference within this time period (Lu et al, 2005; Raghavendra et al, 2004), and that a single dose was able to elicit conditioned place avoidance after a naloxone challenge (Araki et al, 2004). Morphine administration at this dose for 5 days also produced analgesic tolerance (Beaudry et al, 2009), and after only 4 days, produced withdrawal behaviors including increased defecation, urination, salivation, jumping, and wet dog shakes (Pinelli et al, 1997). Finally, this dosing schedule activated glial cells and enhanced proinflammatory cytokine expression in the spinal cord that has been implicated in morphine tolerance and withdrawal-induced hyperalgesia (Raghavendra et al, 2004).

Following day 5 of morphine treatment and 2 days of spontaneous withdrawal (PND 40-41), animals were divided into three treatment groups: (1) saline control, (2) METH, or (3) BUP. The mean baseline bodyweights for the saline control, METH, and BUP groups were 107.3, 127.3, and 109.3 g, respectively. Control animals received subcutaneous volume-matched saline injections and continued on in spontaneous withdrawal for 5 days (PND 42-46). The remaining two groups received either METH $(1 \mathrm{mg} / \mathrm{kg} /$ day $)$ or BUP $(0.1 \mathrm{mg} / \mathrm{kg} /$ day $)$ subchronically for the same 5 days. Following day 5 of opioid replacement treatment, and 3 days of washout (PND 47-49), ${ }^{18}$ FDG scans (scan 2) were again obtained (PND 50).

All images were acquired using a Siemens Inveon microPET. Before scanning, each animal received a single dose of ${ }^{18} \mathrm{FDG}(1.8-2.0 \mathrm{mCi})$ via an intraperitoneal injection. The ${ }^{18}$ FDG doses used are consistent with both intraperitoneal and intravenous doses reported previously using both rats/mice and microPET (Chen et al, 2010; Parthoens et al, 2014; Yang et al, 2014). Perhaps most importantly, however, ${ }^{18}$ FDG doses were specifically designed to produce count rates that did not exceed the dead time correction capabilities of our scanner and images that could be reconstructed using an iterative method (ie, maximum a posteriori (MAP)). Relative to body weight, ${ }^{18} \mathrm{FDG}$ is injected at significantly higher doses in rodents than in humans. These higher doses are necessary in order to achieve both sufficient counting statistics and maximal spatial resolution in these physically smaller rodent brains (Hildebrandt et al, 2008). In addition, published reports have established that higher doses are required for equivalent quality in these images. Specifically, Jagoda et al (2004) determined that roughly the same total amount of radiopharmaceutical used in humans should be used in rodents.

After radiotracer injection, animals were returned to their home cage and left undisturbed for $40 \mathrm{~min}$ to ensure radiotracer uptake. Afterwards, animals were transferred to a clear acrylic chamber, where isoflurane/oxygen was used to induce anesthesia. At 5 min after induction, each animal was transferred to the imaging platform and was secured. Continuous isoflurane/oxygen at $2-2.5 \%$ was administered via nasal cannula for the entire $10 \mathrm{~min}$ static scan. These imaging protocols have previously been shown to adequately reflect glucose metabolism in rodents (Marsteller et al, 2006; Patel et al, 2008; Schiffer et al, 2007).

All microPET images were corrected for attenuation and reconstructed using a MAP probability estimate with 20 iterations as described previously (Schiffer et al, 2009; Vo et al, 2014). Raw data files were uploaded into Pixelwise Modeling Tool software (PXMOD version 3.3, PMOD Technologies LLC), and were aligned to a reference template created using the Paxinos and Watson Sprague-Dawley rat brain atlas. After being placed in anatomical space, images were corrected for injected dose to ensure that regional uptake values would be comparable and were skull-stripped to eliminate extraneous metabolic activity (Schiffer et al, 2006, 2007). Statistical Parametric Mapping (SPM5, Wellcome Trust Centre for Neuroimaging) was used for subsequent postprocessing steps including realignment to an atlas, normalization to a mean template, and smoothing. Between- and within-group comparisons were carried out using paired and two-sample $T$-tests, respectively. Postprocessed images were aligned to the Paxinos and Watson rat brain atlas (Paxinos et al, 1980) and significant regions were identified using $x, y$, and $z$ coordinates. Increases and decreases in relative brain metabolism were visually represented using color mapping. Images were overlaid onto an anatomical cryostat template with metabolic increases set as hot, and metabolic decreases set as winter in the color selection options. The color scale used represents all $\mathrm{T}$ distributions achieving statistical significance (Carrion et al, 2009; Nie et al, 2014; Soto-Montenegro et al, 2009). All corresponding brain areas are significant at a value of $p \leqslant 0.001$ (corrected) with a cluster-extent threshold of $k=0$ voxels. FSL (FMRIB Software Library, Oxford, UK) was used for extraction of significant brain regions using threshold values obtained in SPM (Jenkinson et al, 2012). 
Table I Summary of Group Comparisons and Significant Brain Regions

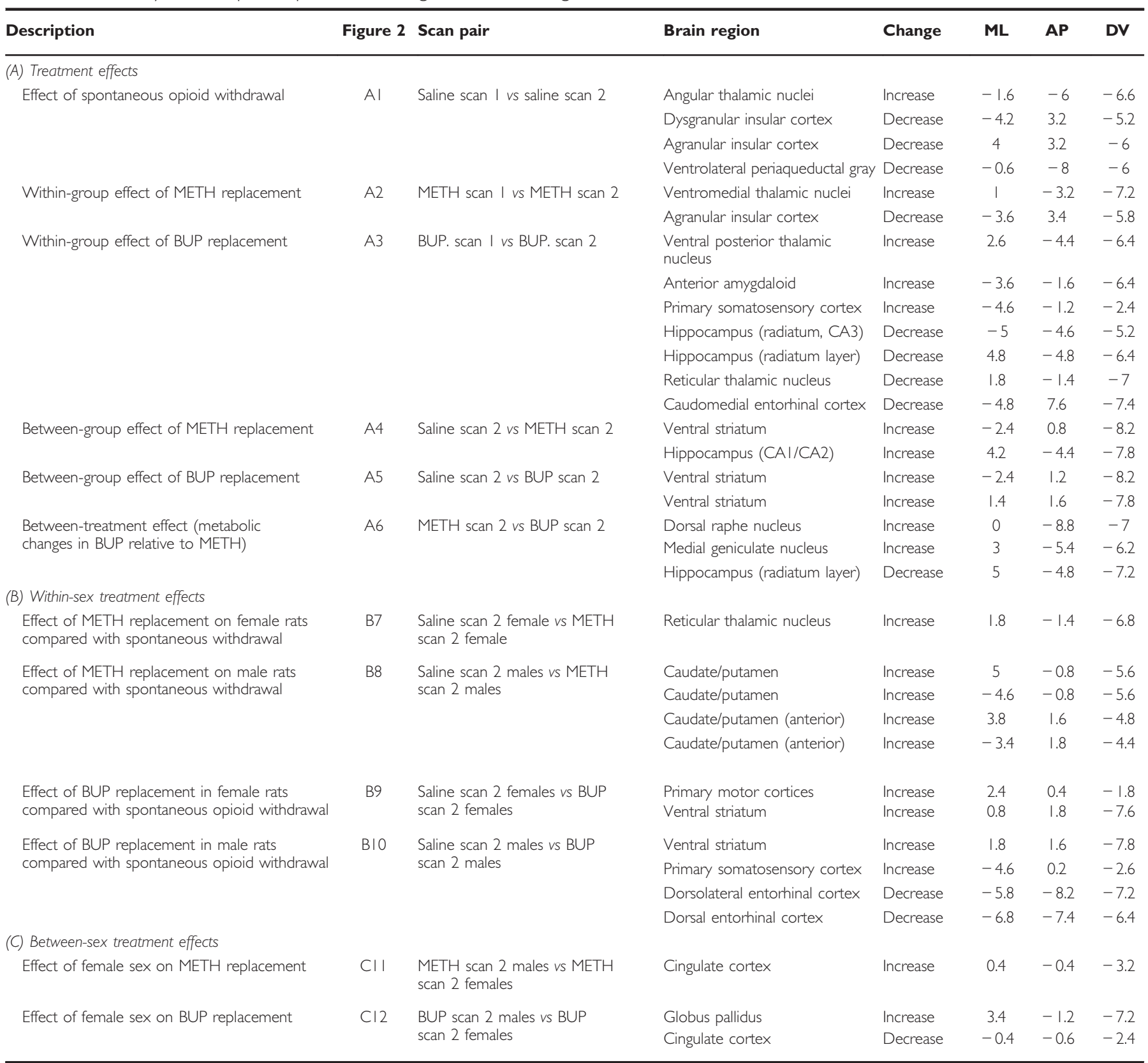

This table provides a summary and description of microPET scan group comparisons organized by (A) treatment effects, (B) within-sex treatment effects, and (C) between-sex treatment effects. METH, BUP, and control (saline) group comparisons are presented. Scan I refers to group baseline scans (pretreatment). Scan 2 refers to the subchronic opioid replacement treatment scans or spontaneous withdrawal scans in the case of saline controls. Brain regions with significant metabolic increases and decreases in glucose metabolism are listed, as well as corresponding medial-lateral (ML), anterior-posterior (AP), and dorsal-ventral (DV) stereotaxic coordinates. All reported increases and decreases are significant at a strict $p$-value threshold of $p \leqslant 0.00$ I (corrected) with a cluster-extent threshold of $k=0$ voxels. A legend of corresponding images from Figure 2 is also shown. The metabolic changes reported are relative to the scan order in the scan pair column. For example, in the first row, saline scan I vs saline scan 2, the metabolic changes reported are the results of scan 2, relative to baseline scan I. The description column is provided to summarize the interpretation of each scan pair.

\section{RESULTS}

Both longitudinal and cross-sectional comparisons within and between groups, respectively, were used to uncover metabolic alterations due to treatment and sex (Table 1). In reality, there are numerous interactions that could be examined. In this study, however, we chose to target our analysis to ${ }^{18} \mathrm{FDG}$ microPET scans acquired at baseline and after treatment. Evaluation at these time points represents an examination of the effects of subchronic opioid exposure and replacement and, therefore, may be clinically relevant to the earliest stages of opioid addiction. 
Specific scan comparisons were utilized to assess (A) treatment effects, (B) within-sex treatment effects, and (C) between-sex treatment effects. Table 1 summarizes all group comparisons, lists significant increases and decreases in regional brain glucose metabolism, and provides a legend for corresponding microPET images highlighted in Figure 2. All reported increases and decreases are significant at a strict $p$-value threshold of $p \leqslant 0.001$ (corrected) with a clusterextent threshold of $k=0$ voxels. These constraints were chosen based on previous recommendations against liberal primary cluster extent thresholds. By eliminating large activations in overlapping anatomical areas, these parameters ensure the statistical validity of the reported regions of interest (Woo et al, 2014).

Spontaneous opioid withdrawal produced changes in both cortical and subcortical brain metabolism (Figure 2, A1). These bilateral changes were noted in the agranular thalamic nuclei (increase), insular cortex (decrease), and periaqueductal gray area (decrease). When disaggregated by sex, several differences were noted. Metabolism in the lateral preoptic area, primary motor cortex, and medial amygdaloid nucleus increased in females compared with males, whereas caudate nucleus, putamen, and medial geniculate nucleus metabolism decreased (images not shown). Subchronic treatment with METH or BUP abolished these withdrawal-associated changes in both sexes. However, both drugs increased ventral striatum metabolism (Figure 2, A4 and A5), consistent with their known effects on reward pathways. In addition, METH produced increased hippocampal metabolism (Figure 2, A4 and A6) and decreased insular cortex metabolism (Figure 2, A2), changes not seen in animals treated with BUP. METH and BUP also produced sex-specific changes that varied by drug. METH increased thalamic metabolism in females (Figure 2, B7) and caudate/putamen metabolism in males (Figure 2, B8). BUP increased motor cortex metabolism in females (Figure 2, B9), but decreased entorhinal cortex metabolism in males (Figure 2, B10). BUP also led to activation of the ventral striatum in both females (Figure 2, B9) and males (Figure 2, B10), compared with control subjects undergoing spontaneous opioid withdrawal. Finally, compared with males, females treated with METH expressed increased cingulate cortex metabolism (Figure 2, C11), whereas females treated with BUP expressed decreased cingulate metabolism and a concomitant increase in globus pallidus metabolism (Figure 2, C12).

\section{DISCUSSION}

Opioid withdrawal produced both similar and unique alterations in regional brain metabolism in male and female animals. Specifically, similar changes were observed in the thalamus, insular cortex, and the periaqueductal gray. However, compared with males, female exhibited increased metabolism in the preoptic area, primary motor cortex, and amygdala, but decreased metabolism in the caudate/putamen and medial geniculate nucleus. Finally, methadone and buprenorphine abolished these changes, yet each produced their own regional metabolic alterations that varied by treatment and sex.

The animal model used in the present study produced distinct metabolic indicators of opioid withdrawal. Opioid withdrawal resulted in specific metabolic patterns in brain regions associated with sensory processing, salience modulation, reward, and memory. These changes are consistent with earlier reports using electrophysiological and behavioral techniques. Zhu et al (2016) recently demonstrated that activity in thalamic projections to the nucleus accumbens mediates behavioral aversion. Furthermore, using muscimol and morphine, Silva and Nobre (2014) demonstrated that GABA and opioid receptors of the periaqueductal gray impact the expression of unconditioned and conditioned fear responses in animals experiencing alcohol withdrawal. Interestingly, although brain lesions to the insula seem to interrupt addictive behaviors, functional neuroimaging studies show that addictive behaviors are associated with reduced insular cortex activity, a disparity that might be explained by regional heterogeneity (Droutman et al, 2015). Finally, opioid withdrawal produced increases in thalamic cyclic AMP, which is thought to play a role in the behavioral physiology of withdrawal (Sadava and Mack, 1986). Despite these data, our knowledge of the neural circuitry involved in opioid withdrawal remains incomplete. However, recent studies have shown that sex likely influences these pathways, and may actually affect treatment outcomes (JimenezTrevino et al, 2011; Ohlin et al, 2015).

Although we observed regional metabolic changes across sex, other alterations were unique to either males or females. Subchronic treatment with METH or BUP abolished these effects. It is important to note, however, that these drugs also produced their own sex-specific changes. Our findings are supported by previous studies revealing clinical and behavioral sex differences in opioid analgesia in the presence of pain and addiction (Becker and Hu, 2008; Craft, 2003; Fillingim and Gear, 2004; Terner et al, 2003). In line with these data, sex appears to alter the expression of spontaneous withdrawal, with males experiencing increased severity and length of withdrawal (Cicero et al, 2002). This might be explained by differences in receptor density as described by Vijay et al (2016), who recently reported that in a group of normal volunteers, males had a greater volume of distribution of $\kappa$-opioid receptors than females. The $\kappa$-opioid receptors in the accumbens shell have been shown to mediate aversive social motivation (Resendez et al, 2012). These findings might be related to neuroanatomical sex differences in the nucleus accumbens core and shell (Forlano and Woolley, 2010). As both METH and BUP bind to this receptor subtype, these findings could have clinical implications regarding the successful treatment of opioid withdrawal. Together, these data suggest that males and females respond to opioids differently. Therefore, they should be studied separately and managed uniquely in an effort to optimize treatment efficacy. Our data further support this notion.

Here, we observed that METH and BUP abolished the regional metabolic changes measured following spontaneous morphine withdrawal, regardless of sex. Interestingly, females expressed variable metabolism in the cingulate gyrus and increased metabolism within the globus pallidus following treatment. Furthermore, males exposed to BUP demonstrated decreases in entorhinal cortex metabolism compared with females. Frenois et al (2005) found that withdrawal memories drive neuronal activity in communicating limbic areas with known involvement in aversive 


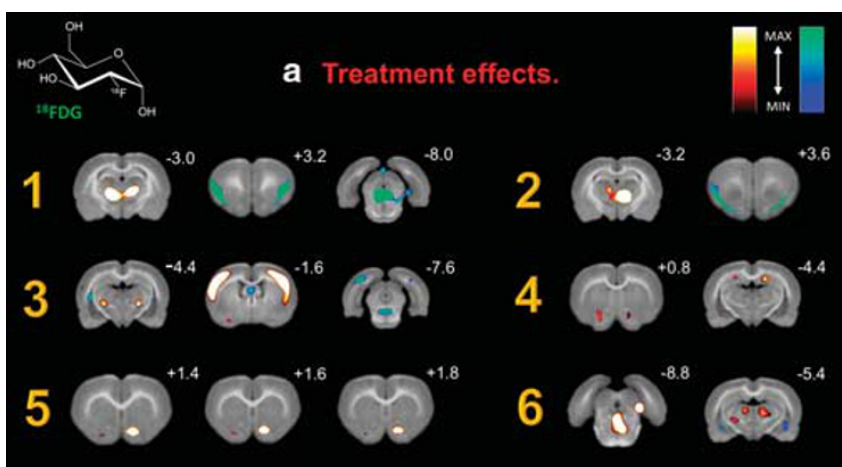

b Within-sex treatment effects.

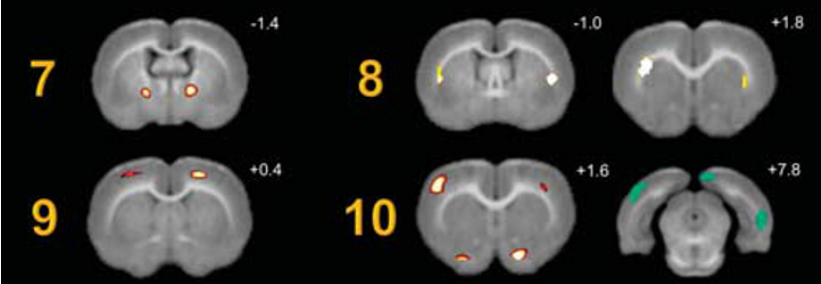

C Between-sex treatment effects.

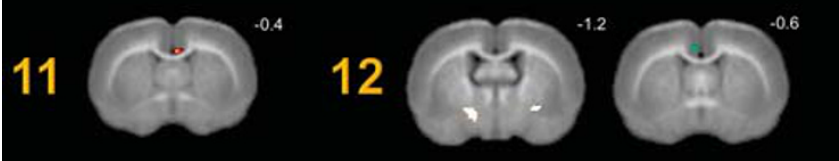

Figure $2{ }^{18}$ FDG microPET images highlighting significant brain regions. Coronal slices of (A) baseline brain metabolism between males and females, (B) changes in brain metabolism following acute withdrawal, and (C) changes in male brain metabolism. Slice distance in millimeters from bregma is noted in the upper right hand comer of each image. Significant increases and decreases in regional brain glucose metabolism are visually represented using hot (red-yellow) and winter (blue-green) color maps, respectively. MAX and MIN refer to the degree of regional radioisotope decay (percent injected dose per gram). The color scale used represents all T distributions achieving statistical significance. All corresponding brain areas are significant at a value of $p \leqslant 0.00$ I (corrected) with a cluster-extent threshold of $k=0$ voxels.

motivational processes. Decreased $\mu$-opioid neurotransmission in limbic and paralimbic circuits seems to correlate with negative affect (Zubieta et al, 2003), an emotional state that induces hyperalgesia in heroin withdrawal (Carcoba et al, 2011). Our data suggest that females preferentially activate limbic structures, regardless of drug treatment, compared with males, who deactivate limbic structures when treated with BUP. Perhaps the metabolic similarities observed following spontaneous withdrawal or opioid replacement produce the initial treatment efficacy experienced by both sexes, whereas the differences detected underlie the treatment failure more commonly observed in males.

Sanchis-Segura and Becker (2016) recently suggested that studies should examine both sex differences and sex similarities, so as to build a more accurate profile of male and female neurobiology and neurophysiology in drugdependent states. In addition, in order to advance our understanding of drug dependence, studies should adopt a multidisciplinary approach, one that goes beyond the explanation of biological responses to opioids. It is important to not only consider the natural course of addiction between sexes, but also the comorbid psychiatric and sociocultural conditions that characterize males and females as well (Buccelli et al, 2016).

The purpose of this preliminary study was to specifically observe regional changes in brain glucose metabolism following opioid withdrawal and replacement. Thus, no formal assessment of locomotor activity or withdrawal behavior was assessed. Pairing this imaging strategy with verified behavioral measures may ultimately be useful in the development of effective pharmacological interventions. This experiment exemplifies how small animal imaging in combination with suitable animal models of opioid dependence and withdrawal may provide an experimental bridge between preclinical studies and human trials.

MicroPET and other imaging modalities offer insight into pharmacokinetics, central nervous system penetration, and dosing that can help accelerate drug development (Pien et al, 2005). The rodent model used in this experiment can be adapted to the study of other novel treatments for opioid abuse. These include BUP implants (Ling et al, 2010; Rosenthal et al, 2013), BUP-gabapentin combination therapy (Sanders et al, 2013), memantine-naltrexone therapy (Bisaga et al, 2011, 2014), slow-release morphine treatment (Jegu et al, 2011), herbal and plant remedies (Gao et al, 2014; Tabatabai et al, 2014), as well as potential immunotherapies including conjugate morphine-heroin vaccines (Li et al, 2011, 2015). Given the abundance of studies on therapeutic intervention, as well as epidemiologic data indicating escalating levels of opioid abuse, additional investigations into existing and novel treatments are warranted.

Current opioid replacement and maintenance therapies are initially effective in both sexes. Unfortunately, over time, they fail more commonly in males. Here, we report that spontaneous opioid withdrawal produced similar regional metabolic changes in males and females. METH or BUP exposure attenuated these changes equally. However, each drug produced unique sex-specific metabolic changes of its own. This mutual attenuation may underlie that period of time when therapeutic efficacy appears similar in both sexes. Concomitantly, these sex-specific differences may contribute to the long-term treatment failure often experienced by males.

These studies were conducted in the service of better understanding the impact of opioid withdrawal and treatment on regional brain glucose metabolism in males and females. These data suggest that novel sex-directed pharmacologic strategies may better serve this rapidly growing patient population. As a result, we may ultimately enhance the quality of life of those currently suffering from opioid dependence, while simultaneously protecting individuals from the potential consequences of its likely progression.

\section{FUNDING AND DISCLOSURE}

The authors declare no conflict of interest.

\section{ACKNOWLEDGMENTS}

We acknowledge the outstanding assistance of Drs David Eidelberg and An Vo and Mr David Bjelke from the Center 
for Neurosciences. We further acknowledge the cyclotron group for radiotracer production. Partial funding for this study was provided by NIH K02 DA22346 to SLD.

\section{REFERENCES}

Anthony JC, Warner LA, Kessler RC (1994). Comparative epidemiology of dependence on tobacco, alcohol, controlled substances, and inhalants: Basic findings from the national comorbidity survey. Exp Clin Psychopharmacol 2: 244-268.

Araki H, Kawakami KY, Jin C, Suemaru K, Kitamura Y, Nagata M et al (2004). Nicotine attenuates place aversion induced by naloxone in single-dose, morphine-treated rats. Psychopharmacology 171: 398-404.

Ball JC, Ross A (1991). The Effectiveness of Methadone Maintenance Treatment: Patients, Programs, Services, and Outcomes. Springer: Washington, DC, pp 283.

Beaudry H, Proteau-Gagne A, Li S, Dory Y, Chavkin C, Gendron L (2009). Differential noxious and motor tolerance of chronic delta opioid receptor agonists in rodents. Neuroscience 161: 381-391.

Becker JB, Hu M (2008). Sex differences in drug abuse. Front Neuroendocrinol 29: 36-47.

Bisaga A, Sullivan MA, Cheng WY, Carpenter KM, Mariani JJ, Levin FR et al (2011). A placebo controlled trial of memantine as an adjunct to oral naltrexone for opioid dependence. Drug Alcohol Depend 119: e23-e29.

Bisaga A, Sullivan MA, Glass A, Mishlen K, Carpenter KM, Mariani JJ et al (2014). A placebo-controlled trial of memantine as an adjunct to injectable extended-release naltrexone for opioid dependence. J Subst Abuse Treat 46: 546-552.

Bonhomme J, Shim RS, Gooden R, Tyus D, Rust G (2012). Opioid addiction and abuse in primary care practice: a comparison of methadone and buprenorphine as treatment options. J Natl Med Assoc 104: 342-350.

Buccelli C, Della Casa E, Paternoster M, Niola M, Pieri M (2016). Gender differences in drug abuse in the forensic toxicological approach. Forensic Sci Int 265: 89-95.

Carcoba LM, Contreras AE, Cepeda-Benito A, Meagher MW (2011). Negative affect heightens opiate withdrawal-induced hyperalgesia in heroin dependent individuals. J Addict Dis 30: 258-270.

Carrion J, CNB Liebling, Reiszel C, Dalal R, Dewey SL, Schiffer WK (2009). Imaging the Conditioned Behavioral Effects of Methamphetamine in Rodents. Brain Imag Behav 3: 176-190.

Center for Behavioral Health Statistics and Quality (2016). 2015 National Survey on Drug Use and Health: Detailed Tables. Substance Abuse and Mental Health Services Administration, Rockville, MD.

Chang HY, Daubresse M, Kruszewski SP, Alexander GC (2014). Prevalence and treatment of pain in EDs in the United States, 2000 to 2010. Am J Emerg Med 32: 421-431.

Chen YY, Shih YYI, Lo YC, Lu PL, Tsang S, Jaw FS et al (2010). MicroPET imaging of noxious thermal stimuli in the conscious rat brain. Somatosens Mot Res 27: 69-81.

Cicero TJ, Nock B, Meyer ER (2002). Gender-linked differences in the expression of physical dependence in the rat. Pharmacol Biochem Behav 72: 691-697.

Compton WM, Volkow ND (2006). Major increases in opioid analgesic abuse in the United States: Concerns and strategies. Drug Alcohol Depend 81: 103-107.

Connock M, Juarez-Garcia A, Jowett S, Frew E, Liu Z, Taylor RJ et al (2007). Methadone and buprenorphine for the management of opioid dependence: a systematic review and economic evaluation. Health Technol Assess 11: 1-171, iii-iv.

Craft RM (2003). Sex differences in opioid analgesia: "from mouse to man". Clin J Pain 19: 175-186.
Daubresse M, Chang HY, Yu YP, Viswanathan S, Shah ND, Stafford RS et al (2013). Ambulatory diagnosis and treatment of nonmalignant pain in the United States, 2000-2010. Med Care 51: 870-878.

Davis WR, Johnson BD (2008). Prescription opioid use, misuse, and diversion among street drug users in New York City. Drug Alcohol Depend 92: 267-276.

Dole VP (1989). Methadone treatment and the acquired immunodeficiency syndrome epidemic. JAMA 262: 1681-1681.

Droutman V, Read SJ, Bechara A (2015). Revisiting the role of the insula in addiction. Trends Cogn Sci 19: 414-420.

Eap CB, Buclin T, Baumann P (2002). Interindividual variability of the clinical pharmacokinetics of methadone - implications for the treatment of opioid dependence. Clin Pharmacokinet 41: 1153-1193.

Fillingim RB, Gear RW (2004). Sex differences in opioid analgesia: clinical and experimental findings. Eur J Pain 8: 413-425.

Forlano PM, Woolley CS (2010). Quantitative analysis of pre- and postsynaptic sex differences in the nucleus accumbens. J Comp Neurol 518: 1330-1348.

Fox HC, Morgan PT, Sinha R (2014). Sex differences in guanfacine effects on drug craving and stress arousal in cocaine-dependent individuals. Neuropsychopharmacology 39: 1527-1537.

Frenois F, Stinus L, Di Blasi F, Cador M, Le Moine C (2005). A specific limbic circuit underlies opiate withdrawal memories. $J$ Neurosci 25: 1366-1374.

Fueger BJ, Czernin J, Hildebrandt I, Tran C, Halpern BS, Stout D et al (2006). Impact of animal handling on the results of F-18FDG PET studies in mice. J Nucl Med 47: 999-1006.

Gao JL, Tu SA, Liu J, Zhang JM, Huang Y, Han M et al (2014). Anjun-ning, a traditional herbal formula, attenuates spontaneous withdrawal symptoms via modulation of the dopamine system in morphine-dependent rats. BMC Complement Altern Med 14: 308.

Haskew M, Wolff K, Dunn J, Beam J (2008). Patterns of adherence to oral methadone: implications for prescribers. J Subst Abuse Treat 35: 109-115.

Hildebrandt IJ, Su H, Weber WA (2008). Anesthesia and other considerations for in vivo imaging of small animals. ILAR J 49: 17-26.

Hitschfeld MJ, Schneekloth TD, Ebbert JO, Hall-Flavin DK, Karpyak VM, Abulseoud OA et al (2015). Female smokers have the highest alcohol craving in a residential alcoholism treatment cohort. Drug Alcohol Depend 150: 179-182.

Jagoda EM, Vaquero JJ, Seidel J, Green MV, Eckelman WC (2004). Experiment assessment of mass effects in the rat: implications for small animal PET imaging. Nucl Med Biol 31: 771-779.

Jegu J, Gallini A, Soler P, Montastruc JL, Lapeyre-Mestre M (2011). Slow-release oral morphine for opioid maintenance treatment: a systematic review. Br J Clin Pharmacol 71: 832-843.

Jenkinson M, Beckmann CF, Behrens TE, Woolrich MW, Smith SM (2012). FSL. Neuroimage 62: 782-790.

Jimenez-Trevino L, Saiz PA, Garcia-Portilla MP, Diaz-Mesa EM, Sanchez-Lasheras F, Buron P et al (2011). A 25-year follow-up of patients admitted to methadone treatment for the first time: mortality and gender differences. Addict Behav 36: 1184-1190.

Johnson RE, Chutuape MA, Strain EC, Walsh SL, Stitzer ML, Bigelow GE (2000). A comparison of levomethadyl acetate, buprenorphine, and methadone for opioid dependence. $N$ Engl J Med 343: 1290-1297.

Kennedy AP, Epstein DH, Phillips KA, Preston KL (2013). Sex differences in cocaine/heroin users: drug-use triggers and craving in daily life. Drug Alcohol Depend 132: 29-37.

Kippin TE, Fuchs RA, Mehta RH, Case JM, Parker MP, BimonteNelson HA et al (2005). Potentiation of cocaine-primed reinstatement of drug seeking in female rats during estrus. Psychopharmacology 182: 245-252.

Kraus ML, Alford DP, Kotz MM, Levounis P, Mandell TW, Meyer M et al (2011). Statement of the American Society Of 
Addiction Medicine Consensus Panel on the use of buprenorphine in office-based treatment of opioid addiction. J Addict Med 5: 254-263.

Li QQ, Luo YX, Sun CY, Xue YX, Zhu WL, Shi HS et al (2011). A morphine/heroin vaccine with new hapten design attenuates behavioral effects in rats. J Neurochem 119: 1271-1281.

Li QQ, Sun CY, Luo YX, Xue YX, Meng SQ, Xu LZ et al (2015). A conjugate vaccine attenuates morphine- and heroin-induced behavior in rats. Int J Neuropsychopharmacol 18: 11.

Ling W, Casadonte P, Bigelow G, Kampman KM, Patkar A, Bailey GL et al (2010). Buprenorphine implants for treatment of opioid dependence: a randomized controlled trial. JAMA 304: 1576-1583.

Ling W, Wesson DR, Charuvastra C, Klett CJ (1996). A controlled trial comparing buprenorphine and methadone maintenance in opioid dependence. Arch Gen Psychiatry 53: 401-407.

Lu L, Chen H, Su W, Ge X, Yue W, Su F et al (2005). Role of withdrawal in reinstatement of morphine-conditioned place preference. Psychopharmacology (Berl) 181: 90-100.

Manchikanti L, Fellows B, Ailinani H, Pampati V (2010). Therapeutic use, abuse, and nonmedical use of opioids: a tenyear perspective. Pain Physician 13: 401-435.

Maremmani I, Gerra G (2010). Buprenorphine-based regimens and methadone for the medical management of opioid dependence: selecting the appropriate drug for treatment. Am J Addict 19: 557-568.

Marsteller DA, Barbarich-Marsteller NC, Fowler JS, Schiffer WK, Alexoff DL, Rubins DJ et al (2006). Reproducibility of intraperitoneal 2-deoxy-2-[F-18]-fluoro-D-glucose cerebral uptake in rodents through time. Nucl Med Biol 33: 71-79.

McCarty D, Perrin NA, Green CA, Polen MR, Leo MC, Lynch F (2010). Methadone maintenance and the cost and utilization of health care among individuals dependent on opioids in a commercial health plan. Drug Alcohol Depend 111: 235-240.

NIDA (1991). Methodological issues in controlled studies on effects of prenatal exposure to drug abuse. NIDA Res Monogr 114: 1-372.

Nie BB, Liu H, Chen KW, Jiang XF, Shan BC (2014). A statistical parametric mapping toolbox used for voxel-wise analysis of FDGPET images of rat brain. PLoS ONE 9: 11.

Nosyk B, Anglin MD, Brissette S, Kerr T, Marsh DC, Schackman BR et al (2013). A call for evidence-based medical treatment of opioid dependence in the United States and Canada. Health Aff (Project Hope) 32: 1462-1469.

Novick DM, Salsitz EA, Joseph H, Kreek MJ (2015). Methadone medical maintenance: an early 21 st-century perspective. J Addict Dis 34: 226-237.

Ohlin L, Fridell M, Nyhlen A (2015). Buprenorphine maintenance program with contracted work/education and low tolerance for non-prescribed drug use: a cohort study of outcome for women and men after seven years. BMC Psychiatry 15: 13.

Parthoens J, Verhaeghe J, Stroobants S, Staelens S (2014). Deep brain stimulation of the prelimbic medial prefrontal cortex: quantification of the effect on glucose metabolism in the rat brain using (18) F FDG microPET. Mol Imag Biol 16: 838-845.

Patel VD, Lee DE, Alexoff DL, Dewey SL, Schiffer WK (2008). Imaging dopamine release with positron emission tomography (PET) and 11C-raclopride in freely moving animals. Neuroimage 41: 1051-1066.

Paxinos G, Watson CRR, Emson PC (1980). AChE-stained horizontal sections of the rat brain in stereotaxic coordinates. $J$ Neurosci Methods 3: 129-149.

Pien HH, Fischman AJ, Thrall JH, Sorensen AG (2005). Using imaging biomarkers to accelerate drug development and clinical trials. Drug Discov Today 10: 259-266.

Pinelli A, Trivulzio S, Ciapponi PM (1997). Quantitative opioid withdrawal signs in rats: effects exerted by clothiapine administration. Fundam Clin Pharmacol 11: 346-355.

Polsky D, Glick HA, Yang J, Subramaniam GA, Poole SA, Woody GE (2010). Cost-effectiveness of extended buprenorphine- naloxone treatment for opioid-dependent youth: data from a randomized trial. Addiction 105: 1616-1624.

Raghavendra V, Tanga FY, DeLeo JA (2004). Attenuation of morphine tolerance, withdrawal-induced hyperalgesia, and associated spinal inflammatory immune responses by propentofylline in rats. Neuropsychopharmacology 29: 327-334.

Resendez SL, Kuhnmuench M, Krzywosinski T, Aragona BJ (2012). kappa-Opioid receptors within the nucleus accumbens shell mediate pair bond maintenance. J Neurosci 32: 6771-6784.

Robbins SJ, Ehrman RN, Childress AR, O'Brien CP (1999). Comparing levels of cocaine cue reactivity in male and female outpatients. Drug Alcohol Depend 53: 223-230.

Rosenthal RN, Ling W, Casadonte P, Vocci F, Bailey GL, Kampman K et al (2013). Buprenorphine implants for treatment of opioid dependence: randomized comparison to placebo and sublingual buprenorphine/naloxone. Addiction 108: 2141-2149.

Ross EJ, Graham DL, Money KM, Stanwood GD (2015). Developmental consequences of fetal exposure to drugs: what we know and what we still must learn. Neuropsychopharmacology 40: 61-87.

Rubonis AV, Colby SM, Monti PM, Rohsenow DJ, Gulliver SB, Sirota AD (1994). Alcohol cue reactivity and mood induction in male and female alcoholics. J Stud Alcohol 55: 487-494.

Sadava D, Mack B (1986). The effect of methadone addiction on cyclic-nucleotide levels in regions of the rat-brain. Life Sci 39: $477-481$.

Sanchis-Segura C, Becker JB (2016). Why we should consider sex (and study sex differences) in addiction research. Addict Biol 21: 995-1006.

Sanders NC, Mancino MJ, Gentry WB, Guise JB, Bickel WK, Thostenson J et al (2013). Randomized, placebo-controlled pilot trial of gabapentin during an outpatient, buprenorphineassisted detoxification procedure. Exp Clin Psychopharmacol 21: 294-302.

Schackman BR, Leff JA, Polsky D, Moore BA, Fiellin DA (2012). Cost-effectiveness of long-term outpatient buprenorphinenaloxone treatment for opioid dependence in primary care. $J$ Gen Intern Med 27: 669-676.

Schiffer WK, Liebling CNB, Reiszel C, Hooker JM, Brodie JD, Dewey SL (2009). Cue-induced dopamine release predicts cocaine preference: positron emission tomography studies in freely moving rodents. J Neurosci 29: 6176-6185.

Schiffer WK, Mirrione MM, Biegon A, Alexoff DL, Patel V, Dewey SL (2006). Serial microPET measures of the metabolic reaction to a microdialysis probe implant. J Neurosci Methods 155: 272-284.

Schiffer WK, Mirrione MM, Dewey SL (2007). Optimizing experimental protocols for quantitative behavioral imaging with (IF)-I-18-FDG in rodents. J Nucl Med 48: 277-287.

Sheynin J, Moustafa AA, Beck KD, Servatius RJ, Casbolt PA, Haber $\mathrm{P}$ et al (2016). Exaggerated acquisition and resistance to extinction of avoidance behavior in treated heroindependent men. J Clin Psychiatry 77: 386-394.

Silva LBC, Nobre MJ (2014). Impaired fear inhibitory properties of $\mathrm{GABA}(\mathrm{A})$ and $\mathrm{mu}$ opioid receptors of the dorsal periaqueductal grey in alcohol-withdrawn rats. Acta Neurobiol Exp 74: 54-66.

Soto-Montenegro M, Vaquero J, Pascau J, Gispert J, Garcia-Barreno P, Desco M (2009). Detection of visual activation in the rat brain using 2-deoxy-2- F-18 fluoro-Dglucose and statistical parametric mapping (SPM). Mol Imag Biol 11: 94-99.

Spanagel R, Weiss F (1999). The dopamine hypothesis of reward: past and current status. Trends Neurosci 22: 521-527.

Tabatabai SM, Dashti S, Doosti F, Hosseinzadeh H (2014). Phytotherapy of opioid dependence and withdrawal syndrome: a review. Phytother Res 28: 811-830. 
Terner JM, Lomas LM, Smith ES, Barrett AC, Picker MJ (2003). Pharmacogenetic analysis of sex differences in opioid antinociception in rats. Pain 106: 381-391.

Trafton JA, Minkel J, Humphreys K (2006). Determining effective methadone doses for individual opioid-dependent patients. PLoS Med 3: e80.

Vassoler FM, Byrnes EM, Pierce RC (2014). The impact of exposure to addictive drugs on future generations: physiological and behavioral effects. Neuropharmacology 76: 269-275.

Vijay A, Wang S, Worhunsky P, Zheng MQ, Nabulsi N, Ropchan J et al (2016). PET imaging reveals sex differences in kappa opioid receptor availability in humans, in vivo. Am J Nucl Med $\mathrm{Mol}$ Imaging 6: 205-214.

Vo A, Volpe BT, Tang CC, Schiffer WK, Kowal C, Huerta PT et al (2014). Regional brain metabolism in a murine systemic lupus erythematosus model. J Cereb Blood Flow Metabol 34: 1315-1320.

Ward J, Hall W, Mattick RP (1999). Role of maintenance treatment in opioid dependence. Lancet 353: 221-226.
Wesson DR, Smith DE (2010). Buprenorphine in the treatment of opiate dependence. J Psychoactive Drugs 42: 161-175.

Wong KP, Sha W, Zhang XL, Huang SC (2011). Effects of administration route, dietary condition, and blood glucose level on kinetics and uptake of F-18-FDG in mice. J Nucl Med 52: 800-807.

Woo CW, Krishnan A, Wager TD (2014). Cluster-extent based thresholding in fMRI analyses: Pitfalls and recommendations. Neuroimage 91: 412-419.

Yang FY, Chang WY, Chen JC, Lee LC, Hung YS (2014), Quantitative assessment of cerebral glucose metabolic rates after blood-brain barrier disruption induced by focused ultrasound using FDG-MicroPET. Neuroimage 90: 93-98.

Zhu YJ, Wienecke CFR, Nachtrab G, Chen XK (2016). A thalamic input to the nucleus accumbens mediates opiate dependence. Nature 530: 219-222.

Zubieta JK, Ketter TA, Bueller JA, Xu YJ, Kilbourn MR, Young EA et al (2003). Regulation of human affective responses by anterior cingulate and limbic mu-opioid neurotransmission. Arch Gen Psychiatry 60: 1145-1153. 